\title{
Appetite sensations as a marker of overall intake
}

\author{
Vicky Drapeau ${ }^{1}$, John Blundell ${ }^{2}$, Fanny Therrien ${ }^{3}$, Claire Lawton ${ }^{2}$, Denis Richard ${ }^{3}$ \\ and Angelo Tremblay ${ }^{1 *}$ \\ ${ }^{1}$ Division of Kinesiology, Laval University, Ste-Foy, Quebec, Canada, G1K 7P4 \\ ${ }^{2}$ Department of Psychology, Leeds University, Leeds, UK, LS2 9JT \\ ${ }^{3}$ Department of Anatomy and Physiology, Laval University and Laval Hospital Research Center, Quebec, Canada, G1K $7 P 4$
}

(Received 14 April 2004 - Revised 17 September 2004 - Accepted 24 September 2004)

\begin{abstract}
The aim of this study was to evaluate the clinical utility of appetite sensations to characterize individual overall energy intake. A group of men $(n$ 28) and women ( $n$ 23) was recruited to record their 'desire to eat', 'hunger', 'fullness' and 'prospective food consumption' (PFC) on visual analogue scales before a standardized meal test, immediately after and every $10 \mathrm{~min}$ for a period of $1 \mathrm{~h}$ after the meal. The $1 \mathrm{~h}$ post-meal area under the curve ( $1 \mathrm{~h} \mathrm{AUC)}$ and the satiety quotient (SQ) were calculated for all appetite sensations. In a second visit, all participants were invited to eat three meals in order to measure total energy intake (TEI) and food preferences. Metabolic rate (MR) was also assessed to derive daily relative energy intake (REI) by subtracting this variable from TEI (TEI- MR=REI). The Three-Factor Eating Questionnaire scores were also calculated for all participants. One h AUC for fullness was the appetite sensation most strongly associated with TEI and REI $(r-0.42, P \leq 0.003$ and $r-0.32, P \leq 0.05$, respectively). SQ for fullness was the only predictor of TEI and REI $(r-0.42, P \leq 0.0003$ and $r-0.30, P \leq 0.05$, respectively). Restraint, disinhibition and hunger scores were not associated with appetite sensation variables. These results suggest that the fullness dimension seems to be a useful appetite sensation to predict long-term TEI and REI. Thus, assessment of appetite sensation such as fullness in response to a fixed load may be useful to evaluate individual overall energy intake.
\end{abstract}

Visual analogue scales: Appetite sensations: Satiety quotient: Energy intake: Overeating: Satiety

Obesity is caused by a combination of factors that inevitably result in an increase in energy intake and/or a decrease in energy expenditure. The assessment of energy intake is an important issue in the characterization of factors implicated in obesity. However, this component of energy balance is difficult to evaluate because under-reporting is common in reported energy intake (Westerterp et al. 1991; Pannemans \& Westerterp, 1993; Johnson et al. 1994; Buhl et al. 1995; Schoeller, 1995). This phenomenon seems to be more important in certain populations such as obese (Lichtman et al. 1992; Heitmann \& Lissner, 1995; Lafay et al. 1997) and restrained individuals (Lafay et al. 1997; Asbeck et al. 2002). In this context, there is a need to develop long-term indicators of total energy intake (TEI) in order better to characterize individual overall intake.

Appetite sensations, which reflect objective and subjective components of appetite control (Stubbs et al. 2000), may have some potential in the development of such a marker. When assessed before a meal, appetite sensations such as 'hunger', 'desire to eat' and 'appetite for a meal' have been shown to be associated with subsequent energy intake (Mattes, 1990; Hulshof et al. 1993; Barkeling et al. 1995;
Porrini et al. 1995). Post-meal appetite sensations also seem to be a good predictor of short-term measured energy intake (Flint et al. 2000). However, the clinical utility of appetite sensations to predict long-term food intake is still uncertain. Only one study has tested the potential utility of appetite sensations in a long-term nutritional follow-up in obese men and women (Doucet et al. 2003). In that study, post-meal appetite ratings predicted $24 \mathrm{~h}$ energy intake, which was measured as long as 2 weeks after the assessment of appetite sensations. However, this relationship was found only in reduced-obese men. Thus, the clinical utility of appetite sensations requires further investigation.

Appetite sensations measured before and after a meal can also reveal information about the satiating capacity of food, which can be expressed as satiety quotient (SQ). Kissileff (1984) first introduced the satiating efficiency of food, which aimed at measuring the extent to which a preload could reduce subjective appetite sensations per unit of intake (e.g. kcal, kJ). Green et al. (1997) extended this concept by taking into account the temporal effect of foods and suggested calculation of the SQ for each appetite sensation measured over time. Differences in SQ for hunger sensation have been observed between meals of high

\footnotetext{
Abbreviations: $1 \mathrm{~h}$ AUC, $1 \mathrm{~h}$ post-meal area under the curve; MR, metabolic rate; PFC, prospective food consumption; REI, relative energy intake; SQ, satiety quotient; TEI, total energy intake; TFEQ, Three-Factor Eating Questionnaire.

* Corresponding author: Dr A. Tremblay, fax +1 418656 2441, email angelo.tremblay@kin.msp.ulaval.ca
} 
and low fixed energy or ad libitum meals and between high- and low-restrained individuals (Green et al. 1997). The usefulness of the SQ needs to be investigated in other populations (e.g. obese). We think that this concept could represent a good marker of individual satiety signal capacity in response to a fixed meal test. In this context, SQ should be associated with long-term TEI: i.e. lower SQ reflecting impaired satiety signals and thus higher overall intake. The present study was therefore performed to further evaluate the clinical utility of appetite sensation responses to a meal test as a potential marker of individual long-term overall intake, and ultimately susceptibility to overeating.

\section{Experimental methods}

\section{Subjects and procedures}

The subjects who participated in this study were involved in another study that investigated the relationship between body weight and stress. Participants were recruited through advertisements placed at the University and in other locations in the Quebec City area. Eligibility of the participants was determined by a telephone interview. Inclusion criteria for the study were age 20-50 years, normal weight $\left(\mathrm{BMI} \leq 27.0 \mathrm{~kg} / \mathrm{m}^{2}\right.$ ), obese (BMI $30.0-35.0 \mathrm{~kg} / \mathrm{m}^{2}$ ) and $/$ or reduced obese $\left(B M I \geq 30 \cdot 0 \mathrm{~kg} / \mathrm{m}^{2}\right)$, in apparently good health, free of medications, sedentary to moderately active (low-intensity physical activities such as brisk walking, three times weekly or less, no more than 30 min per session), no more than five cups of coffee daily, fewer than two alcoholic drinks daily or nine alcoholic drinks weekly, and premenopausal women. The reduced-obese subjects had lost a minimum of $5 \mathrm{~kg}$ in the past 6 months (mean 12.6 (SE 1.6) $\%$ of initial body weight) and were still trying to lose more weight or maintain their body weight. Participants were blind to the study objective. They were aware only of the original nature of the study, i.e. obesity and stress. Each subject received a financial compensation when the study was completed. All participants gave their written consent to take part in the study, which was approved by the Laval University Ethics Committee.

A group of men ( $n$ 28) and women (n 23) with BMI ranging from 18.5 to $43.4 \mathrm{~kg} / \mathrm{m}^{2}$ was invited to participate in two testing sessions which were separated by at least 2 weeks. Except for eight men and seven women, who were considered as reduced-obese subjects, all participants reported a weight variation of $\pm 4 \mathrm{~kg}$ for at least 2 months prior the study.

The first visit started with a standardized breakfast meal test. Thereafter, weight, height (bathing suit, without shoes), waist circumference (Lohman et al. 1988) and percentage body fat were assessed for each participant. Percentage body fat was determined by the underwater weighing technique. The Siri formula (Siri, 1956) was used to estimate percentage of body fat from body density. During this first visit, subjects were also asked to complete the Three-Factor Eating Questionnaire (TFEQ; Stunkard \& Messick, 1985) as validated for the French population (Lluch, 1995), which permits determination of 'dietary restraint', 'disinhibition' and 'susceptibility to hunger' scores. The TFEQ has been shown to have good reliability and validity (Stunkard \& Messick, 1985; Laessle et al. 1989). A food preference questionnaire using a scale from 0 (don't like at all) to 5 (like very much) was used to make sure that all the participants liked the food presented in the study. Subjects scoring less than 3 for more than $50 \%$ of the food items were excluded from this study.

Long-term TEI was measured in the second testing session, which, as stated above, was separated by at least 2 weeks from the first session. The second testing session included three meal tests (standardized breakfast, ad libitum lunch and ad libitum dinner) and the measurement of metabolic rate (MR), which corresponds to energy expenditure, was measured $3 \mathrm{~h}$ after the standardized breakfast. The use of MR three hours after a meal is considered highly significant in the context of the present study because it is measured at a moment when the subject wishes to eat. In addition, a high correlation has been observed between postprandial MR and RMR ( $r$ 0.90; Haugen et al. 2003). Consequently, the ability to classify individuals with postprandial MR is considered identical to what we could obtain if subjects were classified on the basis of the RMR measurement. For the two testing days, participants had to arrive at the laboratory in the morning after an overnight fast (12 h). Moreover, subjects were asked to refrain from alcohol consumption and intense physical activity $24 \mathrm{~h}$ before each testing session. All meals served in the laboratory were consumed under the same conditions: alone, in a quiet place, without reading materials.

\section{Meal test and appetite sensations}

The standardized breakfast was served between 07.30 and 09.30 hours in order to replicate the usual breakfast time of each participant (Appendix 1). The energy content of the meal test was $733 \mathrm{kcal}(3067 \mathrm{~kJ})$ and $599 \mathrm{kcal}(2506 \mathrm{~kJ})$ for men and women, respectively, and had a food quotient of 0.85 . All participants were instructed to eat within $30 \mathrm{~min}$ or less. Before, immediately after and every $10 \mathrm{~min}$ for a period of $1 \mathrm{~h}$ after the standardized breakfast test, subjects were asked to record their appetite sensations such as 'desire to eat', 'hunger', 'fullness' and 'prospective food consumption' (PFC) on visual analogue scales adapted from Hill \& Blundell (1986). Briefly, subjects were asked to indicate, on a scale from 0 to $150 \mathrm{~mm}$, how they felt at the moment of completing the following questions: How strong is your desire to eat? (very weakvery strong); How hungry do you feel? (not hungry at all-as hungry as I ever felt); How full do you feel? (not full at all-very full); How much food do you think you could eat? (nothing at all-a large amount). Subjects were also asked to evaluate their appreciation of the meal.

The appetite ratings before the standardized meal test were taken as the fasting (baseline) appetite sensations. The appetite sensation responses to the standardized meal test were evaluated by calculating the $1 \mathrm{~h}$ post-meal area under the curve ( $1 \mathrm{~h}$ AUC) with the trapezoid method (Doucet et al. 2003). The satiety signal capacity was assessed with the SQ concept adapted from Green et al. (1997). In this study, the SQ was not investigated over time because of the rather short interval of appetite ratings 
after the meal. Instead, we used the mean post-meal appetite sensations to evaluate SQ or the satiety signal capacity in response to a standardized meal test. In addition, SQ values were multiplied by 100 to obtain a more meaningful range of values. Thus, the SQ was calculated for each appetite sensation (AS) with the equation:

$$
\mathrm{SQ}(\mathrm{mm} / \mathrm{kcal})=\frac{(\text { fasting AS }-60 \text { min post-meal AS })}{\text { energy content of test meal }(\mathrm{kcal})} \times 100 \text {. }
$$

Consequently, the theoretical range of possible SQ values was -20 to 20 for men and -25 to 25 for women. A higher SQ for each appetite sensation would mean a greater satiety signal capacity for one individual whereas a lower SQ would represent a blunted satiety signal capacity.

\section{Total and relative energy intake assessments}

After at least a 2-week delay, TEI was calculated over a period of $12 \mathrm{~h}$ with one fixed and two ad libitum meals. First, the same standardized breakfast served at the first visit was provided for each subject and was taken between 07.00 and 08.00 hours at home. The participants were asked to arrive at the laboratory at 11.00 hours. At about 11.45 hours, the subject was invited to eat an ad libitum buffet-type meal for lunch to assess free energy intake and macronutrient preferences. After lunch, participants relaxed in a quiet room until dinner time. The ad libitum dinner was served about $4 \mathrm{~h}$ after the lunch. Appendix 2 presents the foods that were offered during each meal. Participants were instructed not to eat or drink anything else between the three meals, except water. All foods served ad libitum (lunch and dinner) were weighed before and after consumption. The Food Processor software (version 7.60, 2000; ESHA Research, Salem, OR, USA) was used to evaluate TEI during the day and macronutrient preferences at the lunch meal.

Before lunch, MR was determined for each subject by indirect calorimetry. After a $30 \mathrm{~min}$ resting period, expired gas was collected through a mouthpiece over a $15 \mathrm{~min}$ period. The nose was clipped for the entire sampling period. Pulmonary ventilation was determined using a K520 flow transducer (KL Engineering, Sylmar, CA, USA) and gases $\left(\mathrm{CO}_{2}\right.$ and $\left.\mathrm{O}_{2}\right)$ were assayed with a Uras $10 \mathrm{E}$ analyser (Hartmann \& Braun AG, Frankfurt,
Germany). The analyser was calibrated before each test and the Weir formula (Weir, 1949) was used to determine the energy equivalent of $\mathrm{O}_{2}$ volume. MR was used to derive relative energy intake $(\mathrm{REI}=\mathrm{TEI}-\mathrm{MR})$, which represents TEI adjusted for each individual's energy expenditure.

\section{Statistical analyses}

ANOVA was used to assess age, body weight indicators, appetite sensation variables, energy intakes and macronutrient preference differences between men and women. Pearson correlations were performed to evaluate the associations between the appetite sensation variables (fasting state, $1 \mathrm{~h} \mathrm{AUC}$ and SQ) and dependent variables (TEI, macronutrient preferences, REI and TFEQ scores) for the whole group and for men and women separately. Partial correlations adjusted for body weight and BM were also calculated to evaluate the same associations (except for REI). We decided not to use the Bonferroni correction because of the covariation between appetite sensation variables (Perneger, 1998) and there being a reasonable probability of finding an association between appetite sensation variables and energy intake (Stubbs et al. 2000). Stepwise multiple regression analyses (with a probability of 0.05) were also used to determine the best predictor of TEI and REI. All values are expressed as means with standard errors, and differences are considered significant at $P \leq 0.05$. All analyses were performed using Jump Software 3.1.6.2 (SAS Institute Inc., Cary, NC, USA).

\section{Results}

Mean age and BMI were not different between men and women (Table 1). However, men had significantly lower percentage body fat and higher waist circumference than women. Women had higher restraint and disinhibition scores than men (Table 1).

Appetite sensation variables such as fasting, $1 \mathrm{~h}$ AUC and SQ were not significantly different between men and women (Table 2). TEI, especially during the lunch meal, and MR were higher in men than in women (Table 3). In general, subjects appreciated the meals offered (mean scores on visual analogue scales of 114 and $116 \mathrm{~mm}$ for men and women, respectively).

Table 1. Subject characteristics

(Mean values with their standard errors and range)

\begin{tabular}{|c|c|c|c|c|c|c|}
\hline \multirow[b]{2}{*}{ Variable } & \multicolumn{3}{|c|}{ Men (n 28) } & \multicolumn{3}{|c|}{ Women (n 23) } \\
\hline & Mean & SE & Range & Mean & SE & Range \\
\hline Age (years) & $37 \cdot 4$ & 1.4 & $25-50$ & $38 \cdot 2$ & 1.5 & $23-49$ \\
\hline BMI $\left(\mathrm{kg} / \mathrm{m}^{2}\right)$ & $27 \cdot 9$ & 1.0 & $20 \cdot 5-37.4$ & $27 \cdot 4$ & $1 \cdot 1$ & $18 \cdot 5-43 \cdot 4$ \\
\hline Percentage body fat & $23 \cdot 8$ & 1.6 & $4 \cdot 6-36 \cdot 7$ & $31 \cdot 7^{\star \star}$ & $1 \cdot 8$ & $12 \cdot 3-49 \cdot 0$ \\
\hline Waist circumference (cm) & $94 \cdot 8$ & 2.5 & $72 \cdot 3-113 \cdot 6$ & $87 \cdot 1^{\star}$ & $2 \cdot 8$ & $64 \cdot 2-124 \cdot 1$ \\
\hline Restraint (maximum score 21) & 6.9 & 0.8 & $1-18$ & $9 \cdot 3^{*}$ & 0.9 & $3-16$ \\
\hline Disinhibition (maximum score 16 ) & $5 \cdot 3$ & 0.6 & $1-11$ & $7 \cdot 6^{\star \star}$ & 0.6 & $2-13$ \\
\hline Susceptibility to hunger (maximum score 14) & $4 \cdot 1$ & 0.6 & $0-11$ & 5.4 & 0.7 & $0-13$ \\
\hline
\end{tabular}

Mean values were significantly different from those of men: ${ }^{\star} P<0.05 ;{ }^{\star \star} P<0.01$. 
Table 2. Appetite ratings in the fasting state, $1 \mathrm{~h}$ post-meal area under the curve (1 h AUC) and satiety quotient (SQ) for men and women

(Mean values with their standard errors)

\begin{tabular}{|c|c|c|c|c|}
\hline \multirow{2}{*}{$\begin{array}{l}\text { Appetite sensation } \\
\text { variables }\end{array}$} & \multicolumn{2}{|c|}{ Men $(n 28)$} & \multicolumn{2}{|c|}{ Women (n 23) } \\
\hline & Mean & SE & Mean & SE \\
\hline \multicolumn{5}{|c|}{ Appetite ratings in the fasting state (mm) } \\
\hline desire to eat & 77.5 & $7 \cdot 8$ & $75 \cdot 1$ & $8 \cdot 9$ \\
\hline hunger & 83.5 & $7 \cdot 2$ & $66 \cdot 7$ & $8 \cdot 0$ \\
\hline fullness & $39 \cdot 8$ & $5 \cdot \overline{6}$ & $37 \cdot 9$ & $6 \cdot 2$ \\
\hline PFC & 84.5 & $6 \cdot 2$ & $74 \cdot 1$ & $6 \cdot 9$ \\
\hline \multicolumn{5}{|l|}{$1 \mathrm{~h}$ AUC $(\mathrm{mm} \times \mathrm{min})$} \\
\hline AUC for desire to eat & 1302 & 203 & 990 & 223 \\
\hline AUC for hunger & 1372 & 225 & 1115 & 248 \\
\hline AUC for fullness & 6118 & 327 & 6349 & 361 \\
\hline AUC for PFC & 2382 & 331 & 1439 & 365 \\
\hline \multicolumn{5}{|l|}{$\mathrm{SQ}(\mathrm{mm} / \mathrm{kcal})$} \\
\hline SQ for desire to eat & $7 \cdot 6$ & $1 \cdot 1$ & $9 \cdot 7$ & $1 \cdot 2$ \\
\hline$S Q$ for hunger & $8 \cdot 3$ & 1.0 & 7.9 & $1 \cdot 1$ \\
\hline SQ for fullness & $8 \cdot 4$ & 1.0 & $11 \cdot 3$ & $1 \cdot 1$ \\
\hline$S Q$ for PFC & $6 \cdot 1$ & 1.0 & $8 \cdot 3$ & $1 \cdot 1$ \\
\hline
\end{tabular}

PFC, prospective food consumption.

The relationship between appetite sensations and energy intake variables was evaluated for the whole group and for men and women separately even though there was no significant interaction between genders. One $h$ AUC was related with measured TEI in the whole group (Table 4). More specifically, desire to eat, hunger and PFC were positively correlated with TEI, whereas fullness was negatively related with this variable. The $1 \mathrm{~h} \mathrm{AUC}$ for fullness represents the appetite sensation that was most strongly related to TEI. SQ for fullness was the only appetite sensation dimension for which we could observe a significant correlation with TEI (Table 4). The same trend was found when men and women were considered separately (Table 4). However, the relationships between SQ for fullness and TEI were no more significant probably because of the smaller subject number. Adjustment for body weight and BMI decreased the strength of the associations observed between $1 \mathrm{~h}$ AUC or SQ and TEI. However, the association found between $1 \mathrm{~h}$ AUC for fullness and TEI
Table 3. Total energy intake (TEI; standardized breakfast, ad libitum lunch and dinner), metabolic rate (MR), relative energy intake (REI; = TEI - MR), energy intake (EI) and macronutrient preferences at the buffet-type lunch for men and women

(Mean values with their standard errors)

\begin{tabular}{|c|c|c|c|c|}
\hline \multirow[b]{2}{*}{ Variable } & \multicolumn{2}{|c|}{ Men (n 28) } & \multicolumn{2}{|c|}{ Women (n 23) } \\
\hline & Mean & SE & Mean & SE \\
\hline TEl $(\mathrm{kcal} / \mathrm{d}) \dagger$ & 2634 & 85 & $2081^{\star \star *}$ & 102 \\
\hline$(\mathrm{kJ} / \mathrm{d})$ & 11015 & 357 & $8699^{\star \star *}$ & 425 \\
\hline $\mathrm{MR}(\mathrm{kcal} / \mathrm{d}) \ddagger$ & 1962 & 53 & $1628^{\star \star *}$ & 59 \\
\hline$(\mathrm{kJ} / \mathrm{d})$ & 8204 & 221 & $6810^{\star \star \star}$ & 246 \\
\hline REl (kcal/d)§ & 676 & 102 & 503 & 119 \\
\hline$(\mathrm{kJ} / \mathrm{d})$ & 2828 & 411 & 2106 & 498 \\
\hline $\mathrm{El}$ at lunch (kcal) & 1113 & 61 & $795^{\star \star}$ & 67 \\
\hline$(\mathrm{kJ})$ & 4654 & 255 & $3325^{\star \star}$ & 281 \\
\hline $\begin{array}{l}\text { Carbohydrates at lunch } \\
(\% \text { TEI })\end{array}$ & $42 \cdot 0$ & $1 \cdot 8$ & 39.6 & 1.9 \\
\hline Lipids at lunch (\% TEI) & $35 \cdot 9$ & 1.4 & $39 \cdot 6$ & 1.5 \\
\hline Proteins at lunch (\% TEI) & $22 \cdot 1$ & $1 \cdot 3$ & $20 \cdot 8$ & $1 \cdot 1$ \\
\hline $\mathrm{El}$ at dinner (kcal)† & 779 & 50 & 630 & 60 \\
\hline$(\mathrm{kJ})$ & 3258 & 209 & 2635 & 251 \\
\hline
\end{tabular}

Mean values were significantly different from those of men: ${ }^{\star \star} P<0.001$; ${ }^{* \star *} P<0.0001$.

† Men, $n$ 27; women, $n 19$.

$\ddagger$ Men, $n$ 26; women, $n 21$.

$\S$ Men, $n$ 25; women, $n 17$.

was still significant, except for the men. Relationships between $1 \mathrm{~h}$ AUC or SQ for all appetite sensations and REI also revealed that only $1 \mathrm{~h}$ AUC or SQ for fullness was associated with REI (Fig. 1(a) and (b)). The same pattern of relationship was observed when considering macronutrient intake and dietary densities as dependent variables (data not shown).

Even though adjustments for body weight and BMI affected our results, no consistent pattern of correlation was found between appetite sensation variables (1 h AUC or SQ) and participant characteristics such as body weight, BMI, percentage body fat and MR, either in the whole sample or for each sex separately. In women, body weight was negatively correlated with SQ for desire to eat $(r-0.46, P=0.03)$ and SQ for PFC $(r-0.49$, $P=0.02)$ only, and BMI was negatively correlated with

Table 4. Correlation coefficients between appetite sensations and total energy intake for the whole group and for men and women separately: non-adjusted (NA) and adjusted (A) for body weight and BMI

\begin{tabular}{|c|c|c|c|c|c|c|}
\hline & \multicolumn{2}{|c|}{ Whole group } & \multicolumn{2}{|c|}{ Men } & \multicolumn{2}{|c|}{ Women } \\
\hline & NA & A & NA & $A$ & NA & A \\
\hline \multicolumn{7}{|l|}{$1 \mathrm{~h}$ AUC $(\mathrm{mm} \times \mathrm{min})$} \\
\hline AUC for desire to eat & $0 \cdot 30^{\star}$ & 0.17 & $0 \cdot 20$ & 0.14 & 0.38 & 0.36 \\
\hline AUC for hunger & $0.37^{\star \star}$ & 0.24 & 0.36 & 0.26 & $0.46^{\star}$ & 0.42 \\
\hline AUC for fullness & $-0.42^{\star \star \star}$ & $-0.32^{*}$ & $-0.42^{*}$ & -0.28 & $-0.61^{\star *}$ & $-0.54^{\star *}$ \\
\hline AUC for PFC & $0.33^{*}$ & 0.17 & 0.20 & 0.20 & 0.35 & 0.37 \\
\hline \multicolumn{7}{|l|}{$\mathrm{SQ}(\mathrm{mm} / \mathrm{kcal})$} \\
\hline SQ for desire to eat & 0.03 & 0.26 & 0 & 0 & $0 \cdot 20$ & 0.37 \\
\hline$S Q$ for hunger & 0.03 & 0.08 & 0 & 0.14 & 0.05 & 0.17 \\
\hline SQ for fullness & $-0.42^{\star \star \star}$ & -0.26 & -0.35 & -0.30 & -0.39 & -0.32 \\
\hline$S Q$ for PFC & 0.20 & 0.05 & 0.09 & 0.10 & 0.10 & 0.02 \\
\hline
\end{tabular}

$1 \mathrm{~h}$ AUC, $1 \mathrm{~h}$ post-meal area under the curve; PFC, prospective food consumption; SQ, satiety quotient. Statistically significant correlation: ${ }^{\star} P<0.05 ;{ }^{\star \star} P<0.01 ;{ }^{\star \star \star} P<0.001$. 

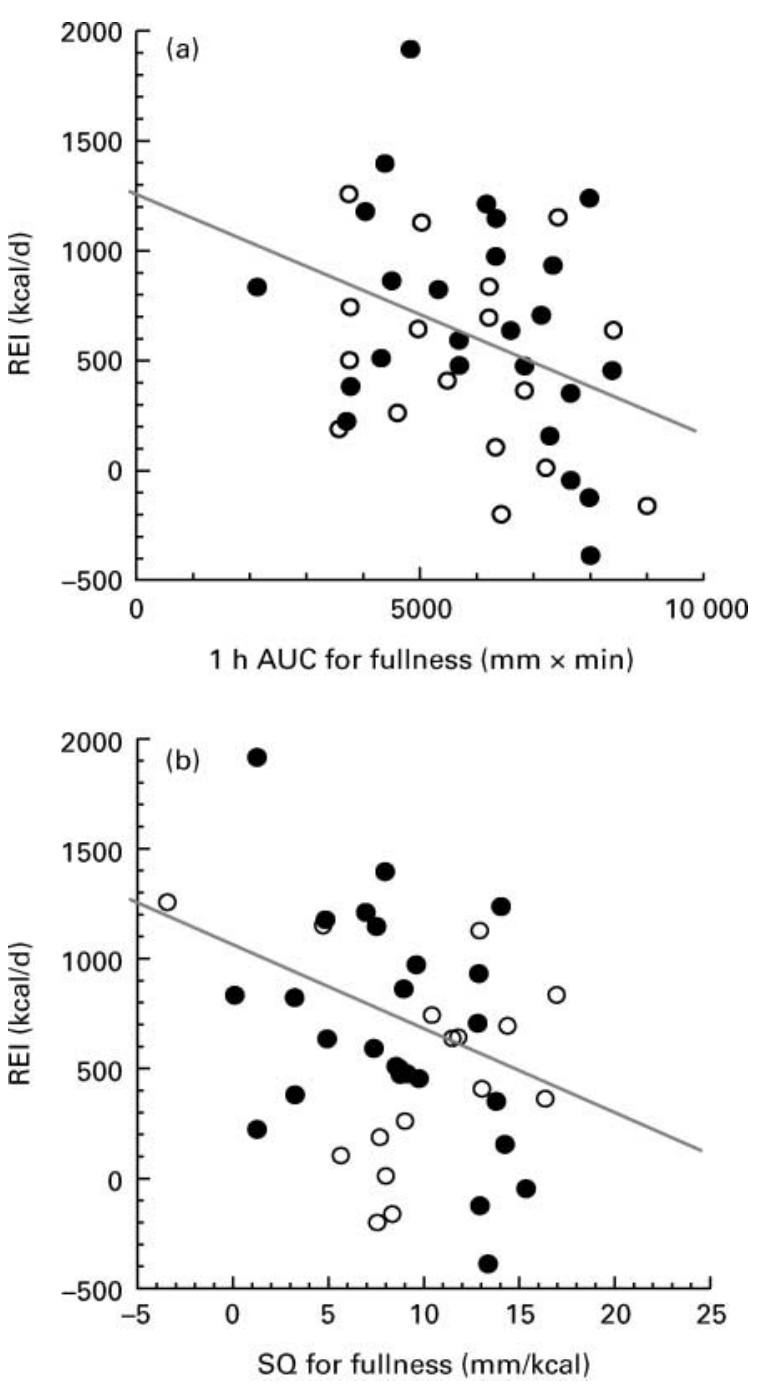

Fig. 1. Relationship between relative energy intake (REI) and (a) $1 \mathrm{~h}$ post-meal area under the curve ( $1 \mathrm{~h} \mathrm{AUC)}$ for fullness and (b) satiety quotient $(\mathrm{SQ})$ for fullness in men $(\bullet)$ and women $(\mathrm{O})$. Correlation between REI and $1 \mathrm{~h}$ AUC for fullness: $r-0.32^{*},-0.36$ and -0.30 for the whole group, men and women, respectively. Correlation between REI and SQ for fullness: $r-0.30^{*},-0.42^{*}$ and -0.08 for the whole group, men and women, respectively. Statistically significant correlation: ${ }^{*} P \leq 0.05$.

SQ for PFC $(r-0.49, P=0.02)$. In men, only BMI was positively correlated with SQ for fullness ( $r$ 0.44, $P=0.02)$. No association was found between appetite sensation variables ( $1 \mathrm{~h}$ AUC and SQ) and MR in men. In women, MR was positively correlated with $1 \mathrm{~h}$ AUC for PFC $(r 0.42, P=0.05)$, and negatively correlated with SQ for desire to eat $(r-0.64, P=0.002)$ and SQ for PFC $(r-0.69, P=0.0005)$.

Because appetite sensation related to fullness represented the best predictor of TEI, we further examined this appetite sensation variable. SQ for fullness was negatively correlated with percentage lipid intake in women $(r-0.60, P=0.002)$. The fullness SQ was also correlated with fullness $1 \mathrm{~h}$ AUC (whole group, $r$ 0.55; men, $r$ 0.72; women, $r$ 0.40, $P(0 \cdot 0001)$. In general, $1 \mathrm{~h}$ AUC and SQ for fullness were not related with any TFEQ score. In a stepwise model including body weight, BMI, $1 \mathrm{~h}$ AUC and SQ for fullness, the $1 \mathrm{~h}$ AUC for fullness explained an additional $7 \%$ of the variance in TEI $(P \leq 0.05)$ after body weight and BMI had explained $32 \%$ of the variance whereas only the $1 \mathrm{~h}$ AUC for fullness explained $10 \%$ of the variance in REI $(P \leq 0 \cdot 05)$. The addition of one or more TFEQ scores in the stepwise model did not influence these results.

\section{Discussion}

This study was performed as a first step in evaluating the usefulness of appetite sensations measured at a meal test to predict individual overall energy intake. Post-meal appetite sensation for fullness was found to be a good predictor of TEI measured after a relatively long delay ( $>2$ weeks) following the assessment of appetite sensations. Such a delay between the appetite sensation assessment and energy intake was a significant feature of this study because it represents an important dimension to consider when the results are transposed in a clinical context. Appetite sensations for fullness also predicted REI, which suggests that some individuals expressed higher overall energy intake. Overeating can be a concept difficult to measure accurately, particularly in a cross-sectional context. In this study, we used the amount of energy consumed over MR as a measure of REI. This variable is not a direct measurement of overeating. However, since the participants tested in this study were all sedentary to moderately active and reported a weight variability offering different states of energy balance $( \pm 4 \mathrm{~kg})$, higher differences between TEI and MR are expected to represent an estimate of excess energy intake or higher overall energy intake.

Our results are in accordance with those of Doucet et al. (2003), who showed that $1 \mathrm{~h}$ AUC for all appetite sensations was associated with TEI measured up to 2 weeks after the appetite ratings. However, this was found only in reduced-obese men when evaluating obese men and women before and after a weight-loss intervention. In addition, the correlations found in that study were higher than those in the present study $(0.70-0.90 v .0 .35-0.41)$. The different foods offered to measure TEI, the longer period of time between the meal test and the energy intake measurement for some subjects in our study, and a different testing environment could partly explain these different results. The fact that our subjects were not engaged in a weight-loss intervention could also have influenced our results. It has been shown that restraint scores are higher in individuals seeking participation in weightloss interventions (Boschi et al. 2001) as well as in reduced-obese individuals (Bjorvell et al. 1994; Clark et al. 1994; Pekkarinen et al. 1996; Wadden et al. 1997; Foster et al. 1998; Kiernan et al. 2001). In our study, we did not observe a strong influence of TFEQ scores on appetite sensation responses after the meal test. It is therefore possible that in our population the level of restraint was not as high as that in obese individuals before and after a weight-loss intervention, even in our reduced-obese group. Because the weight loss in the reduced-obese group had been achieved over the previous 6 months, their levels of restraint could have been lower at the moment of the testing than during or immediately after 
their weight loss. The fact that the mean restraint score of men and women in our study was comparable with that found in normal-weight non-dieters (Klem et al. 1998) supports this assumption.

It should also be stated that TEI at a meal can be influenced by factors other than appetite sensations and eating behaviours, such as palatability, external factors, gender, body weight and genes (de Castro, 1993; Yeomans, 1996; Tuomisto et al. 1998; Jéquier \& Tappy, 1999). The fact that our subjects ate their meals ad libitum under the same laboratory conditions probably attenuated the impact of external factors on food intake measurements. In addition, we did not find a gender interaction for the relationship between appetite sensations and TEI or REI. In this study, body weight and BMI could explain in part the relationship between appetite sensations and TEI. However, since $1 \mathrm{~h}$ AUC for fullness was still associated with TEI after body weight and BMI adjustments, and we did not observe a clear pattern of relationship between appetite sensations and participant characteristics, it is likely that individuals showing lower $1 \mathrm{~h}$ AUC for fullness expressed higher overall energy intake regardless of their current body weight. These results suggest that these individuals could be at higher risk of overeating. The negative relationships found between $1 \mathrm{~h}$ AUC for fullness and REI support this hypothesis.

The SQ was used in this study to measure satiety signal

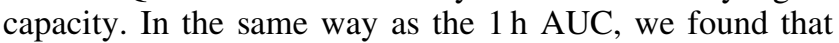
the SQ for fullness was the most sensitive to predict TEI as well as REI. This could be explained by the fact that fullness is probably the easiest appetite sensation to detect because it is more physical (i.e. related with stomach fullness) than the other three motivational measures. Accordingly, fullness sensation has been identified as one of the most common reasons to stop a meal (Tuomisto et al. 1998). In addition, the higher SQ for fullness was also associated with lower fat preferences in women. It is, however, impossible to identify which comes first. Since a high-fat diet has been associated with excess energy intake and lower satiating capacity (Lawton et al. 1993), it could be argued that a habitual high-fat diet explains the lower satiety signal capacity shown by the fullness SQ. On the other hand, an impaired satiety signal capacity could predispose to overeating and thus to a high fat consumption. Nevertheless, the SQ for fullness seemed to measure a separate construct of appetite sensation response to a meal since it was not highly correlated with $1 \mathrm{~h}$ AUC for fullness. This is probably due to the fact that the SQ takes into account pre-meal appetite feelings, which is not the case for $1 \mathrm{~h}$ AUC.

The fact that we did not find an impact of restraint scores on SQ could be surprising since this behaviour has been shown to influence energy intake (Provencher et al. 2003). In contrast to our result, Green et al. (1997) found that restraint score did influence SQ. They observed higher SQ for hunger over time after a lunch with lower fixed energy compared with higher fixed energy in highly restrained normal-weight women, whereas there was no difference for unrestrained women. The fact that testing was performed in different populations and that the mean restraint score in our study was not so high could be responsible for these apparently diverging results.
It is interesting to note that we found very low fullness SQ values for some subjects (see Fig. 1(b)). This means that some subjects experienced almost no change in fullness after the meal. This is unlikely to be due to a misinterpretation of the question, because the research assistant reviewed these answers with the subjects to make sure that they had fully understood the question. These subjects were reporting that food could sometime stimulate their appetite. This phenomenon may have occurred in previous studies but may have been overlooked because mean group values are usually presented instead of individual mean values. This can only be seen when subjects are examined individually. We also cannot discard the fact that perhaps the amount of food served at this meal test was insufficient for some subjects. However, if the amount of food had been insufficient, we should have seen a clear negative relationship between SQ for fullness and body weight, which was not the case. In the context of this study, lower SQ could suggest that some individuals had impaired satiety signals (for fullness) which results in higher TEI and REI. Even if genetic influences have been found for appetite sensations such as hunger before and after meals (de Castro, 1999), it is difficult to determine if a lower satiety capacity is the cause of higher TEI because TEI itself could influence appetite sensations. These individuals display an interesting phenotype for further studies.

One objective of this study was to develop a simple, easy to administer and inexpensive clinical test that could predict individual overall long-term energy intake. One limitation of this study could be related to the standardized breakfast test, which is probably not the optimal tool to use in experimental settings because it does not consider differences in subjects' normal meal size and/or body weight. Nevertheless, this test has the potential to discriminate differences in energy intake over the rest of the day since we used ad libitum lunch and dinner to measure spontaneous energy intake. The use of a standardized breakfast also has the advantage of decreasing social bias that could be observed with an ad libitum meal test. Another possible limitation of this study concerned the potential impact of the artificial meal pattern employed to measure food intake (one fixed meal and two ad libitum meals). We are aware that this method does not permit reproduction of participants' normal eating pattern such as meal sizes, meal frequencies and temporal distribution. Nevertheless, this strategy has the advantage of standardizing the eating pattern and mimicking free-living conditions to some extent. This is supported by the fact that we found a positive relationship between TEI (after fixed breakfast, ad libitum lunch and dinner) and mean TEI derived from a $3 \mathrm{~d}$ dietary record $(r-0.51, P=0.0006)$ that was completed in the initial study. In the context of this study, a non-standardized meal pattern could represent a confounding factor that could have decreased the likelihood of finding such a relationship. It is also important to consider the short period $(4-5 \mathrm{~h})$ of free food intake measurement used in this study. Accordingly, this method, which permits evaluation of free food intake only over two consecutive meals, could limit extrapolation of these results to individual overall diets. Finally, even if we did not find 
relationships between appetite sensation and TFEQ scores, some eating behaviours, particularly restraint level, could have influenced measured energy intake and thus may have blunted the ability to identify associations. It is not excluded that the TFEQ scores could influence appetite sensations in other contexts and/or populations.

In summary, this study suggests that appetite sensation responses to a test meal could be useful in a clinical context to predict individual overall long-term energy intake. Appetite sensation regarding fullness ( $1 \mathrm{~h}$ AUC and SQ) seems to be the best marker of TEI variations. Ultimately, appetite sensations could also help to characterize individuals expressing higher REI and thus a higher susceptibility to overeat. Other longitudinal studies should be performed to confirm these findings. Furthermore, the SQ concept, which represents an individual's satiety capacity, merits attention in other studies investigating different phenotypes or different meal test challenges.

\section{Acknowledgements}

This study was supported by the Canadian Institutes of Health Research. A. T. is partly funded by the Canada Research Chair in Physical Activity, Nutrition, and Energy Balance.

\section{References}

Asbeck I, Mast M, Bierwag A, Westenhofer J, Acheson KJ \& Muller MJ (2002) Severe underreporting of energy intake in normal weight subjects: use of an appropriate standard and relation to restrained eating. Public Health Nutr 5, 683-690.

Barkeling B, Rossner S \& Sjoberg A (1995) Methodological studies on single meal food intake characteristics in normal weight and obese men and women. Int J Obes Relat Metab Disord 19, 284-290.

Bjorvell H, Aly A, Langius A \& Nordstrom G (1994) Indicators of changes in weight and eating behaviour in severely obese patients treated in a nursing behavioural program. Int $J$ Obes Relat Metab Disord 18, 521-525.

Boschi V, Iorio D, Margiotta N, D’Orsi P \& Falconi C (2001) The Three-Factor Eating Questionnaire in the evaluation of eating behaviour in subjects seeking participation in a dietotherapy programme. Ann Nutr Metab 45, 72-77.

Buhl KM, Gallagher D, Hoy K, Matthews DE \& Heymsfield SB (1995) Unexplained disturbance of body weight regulation: diagnostic outcome assessed by doubly labeled water and body composition analyses in obese patients reporting low energy intakes. Am J Diet Assoc 95, 1393-1400.

Clark MM, Marcus BH, Pera V \& Niaura RS (1994) Changes in eating inventory scores following obesity treatment. Int J Eat Disord 15, 401-405.

de Castro J (1993) Independence of genetic influences on body size, daily intake, and meal patterns of humans. Physiol Behav 54, 633-639.

de Castro J (1999) Heritability of hunger relationships with food intake in free-living humans. Physiol Behav 67, 249-258.

Doucet E, St-Pierre S, Almeras N \& Tremblay A (2003) Relation between appetite ratings before and after a standard meal and estimates of daily energy intake in obese and reduced obese individuals. Appetite 40, 137-143.

Flint A, Raben A, Blundell JE \& Astrup A (2000) Reproducibility, power and validity of visual analogue scales in assessment of appetite sensations in single test meal studies. Int $J$ Obes Relat Metab Disord 24, 38-48.

Foster GD, Wadden TA, Swain RM, Stunkard AJ, Platte P \& Vogt RA (1998) The Eating Inventory in obese women: clinical correlates and relationship to weight loss. Int J Obes Relat Metab Disord 22, 778-785.

Green SM, Delargy H, Joanes D \& Blundell JE (1997) A satiety quotient: a formulation to assess the satiating effect of food. Appetite 29, 291-303.

Haugen HA, Melanson EL, Tran ZV, Kearney JT \& Hill JO (2003) Variability of measured resting metabolic rate. Am J Clin Nutr 78, 1141-1145.

Heitmann BL \& Lissner L (1995) Dietary underreporting by obese individuals - is it specific or non-specific? $\mathrm{Br}$ Med $\mathrm{J}$ 311, 986-989.

Hill AJ \& Blundell JE (1986) The effects of a high-protein or high-carbohydrate meal on subjective motivation to eat and food preferences. Nutr Behav 3, 133-144.

Hulshof T, De Graaf C \& Weststrate JA (1993) The effects of preloads varying in physical state and fat content on satiety and energy intake. Appetite 21, 273-286.

Jéquier E \& Tappy L (1999) Regulation of body weight in humans. Physiol Rev 79, 451-480.

Johnson RK, Goran MI \& Poehlman ET (1994) Correlates of over- and underreporting of energy intake in healthy older men and women. Am J Clin Nutr 59, 1286-1290.

Kiernan M, King AC, Stefanick ML \& Killen JD (2001) Men gain additional psychological benefits by adding exercise to a weight-loss program. Obes Res 9, 770-777.

Kissileff HR (1984) Satieting efficiency and strategy for conducting food loading experiments. Neurosci Biobehav Rev 8, 129-135.

Klem ML, Wing RR, McGuire MT, Seagle HM \& Hill JO (1998) Psychological symptoms in individuals successful at long-term maintenance of weight loss. Health Psychol 17, 336-345.

Laessle RG, Tuschl RJ, Kotthaus BC \& Pirke KM (1989) A comparison of the validity of three scales for the assessment of dietary restraint. J Abnorm Psychol 98, 504-507.

Lafay L, Basdevant A, Charles MA, Vray M, Balkau B, Borys JM, Eschwege E \& Romon M (1997) Determinants and nature of dietary underreporting in a free-living population: the Fleurbaix Laventie Ville Sante (FLVS) Study. Int J Obes Relat Metab Disord 21, 567-573.

Lawton CL, Burley VJ, Wales JK \& Blundell JE (1993) Dietary fat and appetite control in obese subjects: weak effects on satiety. Int J Obes Relat Metab Disord 17, 409-416.

Lichtman SW, Pisarska K, Berman ER, Pestone M, Dowling H, Offenbacher E, Weisel H, Heshka S, Matthews DE \& Heymsfield SB (1992) Discrepancy between self-reported and actual caloric intake and exercise in obese subjects. $N$ Engl $J$ Med 327, 1893-1898.

Lluch A (1995) Identification des conduites alimentaires par approches nutritionnelles et psychométriques: implications thérapeutiques et préventives dans l'obésité humaine (Identification of food intake behaviors by nutritional and psychometric means: implications for prevention and treatment of human obesity). Thesis, Université Henri Poincaré, Nancy.

Lohman T, Roche A \& Martorell R (1988) The Airlie (VA) consensus. In Standardization of Anthropometric Measurements, pp. 39-80 [T Lonman, A Roche and R Martorell, editors]. Champaign, IL: Human Kinetics Publishers.

Mattes R (1990) Hunger ratings are not a valid proxy measure of reported food intake in humans. Appetite 15, 103-113.

Pannemans DL \& Westerterp KR (1993) Estimation of energy intake to feed subjects at energy balance as verified by 
doubly labelled water: a study in the elderly. Eur J Clin Nutr 47, 490-496.

Pekkarinen T, Takala I \& Mustajoki P (1996) Two year maintenance of weight loss after a VLCD and behavioural therapy for obesity: correlation to the scores of questionnaires measuring eating behaviour. Int J Obes Relat Metab Disord 20, 332-337.

Perneger TV (1998) What's wrong with Bonferroni adjustments. Br Med J 316, 1236-1238.

Porrini M, Crovetti R, Testolin G \& Silva S (1995) Evaluation of satiety sensations and food intake after different preloads. Appetite 25, 17-30.

Provencher V, Drapeau V, Tremblay A, Despres JP \& Lemieux S (2003) Eating behaviors and indexes of body composition in men and women from the Quebec family study. Obes Res 11, $783-792$.

Schoeller DA (1995) Limitations in the assessment of dietary energy intake by self-report. Metabolism 44, 18-22.

Siri WE (1956) The gross composition of the body. Adv Biol Med Phys 4, 239-280.

Stubbs RJ, Hughes DA, Johnstone AM, Rowley E, Reid C, Elia M, Stratton R, Delargy H, King N \& Blundell JE (2000) The use of visual analogue scales to assess motivation to eat in human subjects: a review of their reliability and validity with an evaluation of new hand-held computerized systems for temporal tracking of appetite ratings. Br J Nutr 84, 405-415.

Stunkard AJ \& Messick S (1985) The three-factor eating questionnaire to measure dietary restraint, disinhibition and hunger. J Psychosom Res 29, 71-83.

Tuomisto T, Tuomisto MT, Hetherington M \& Lappalainen R (1998) Reasons for initiation and cessation of eating in obese men and women and the affective consequences of eating in every day situations. Appetite 30, 211-222.

Wadden TA, Berkowitz RI, Vogt RA, Steen SN, Stunkard AJ \& Foster GD (1997) Lifestyle modification in the pharmacologic treatment of obesity: a pilot investigation of a potential primary care approach. Obes Res 5, 218-226.

Weir JB (1949) New methods for calculating metabolic rate with special reference to protein metabolism. J Physiol 109, 1-9.

Westerterp K, Verboeket-van de Venne WPHG, Meijer JAL \& Hoor F (1991) Self-reported intake as a measure for energy intake. A validation against the doubly labelled water. Obes Res 91, 17-22.

Yeomans MR (1996) Palatability and the microstructure of eating in humans: the appetiser effect. Appetite 26, 119-133.

\section{Appendix 1}

Composition of the breakfast meal test for men and women

\begin{tabular}{|c|c|c|c|c|c|c|}
\hline \multirow{2}{*}{ Food } & \multicolumn{3}{|c|}{ Men } & \multicolumn{3}{|c|}{ Women } \\
\hline & Weight (g) & \multicolumn{2}{|c|}{ Energy } & Weight (g) & \multicolumn{2}{|c|}{ Energy } \\
\hline White bread & 100 & $261 \cdot 2$ & $1092 \cdot 3$ & 80 & $209 \cdot 0$ & $874 \cdot 0$ \\
\hline Butter & 12 & $88 \cdot 6$ & 370.5 & 12 & $88 \cdot 6$ & 370.5 \\
\hline Peanut butter & 16 & 102.5 & $428 \cdot 7$ & 16 & 102.5 & $428 \cdot 6$ \\
\hline Orange juice & 250 & $116 \cdot 3$ & 486.4 & 250 & $116 \cdot 3$ & $486 \cdot 4$ \\
\hline Total & 418 & $733 \cdot 1$ & $3065 \cdot 8$ & 378 & $598 \cdot 7$ & 2503.7 \\
\hline
\end{tabular}

\section{Appendix 2}

Foods served during each meal for the assessment of total energy intake

\begin{tabular}{|c|c|c|c|c|}
\hline $\begin{array}{l}\text { Standardized breakfast } \\
\text { (07.00-08.00 hours) }\end{array}$ & & $\begin{array}{l}\text { Ad libitum lunch } \\
\text { (12.00 hours) }\end{array}$ & & $\begin{array}{l}\text { Ad libitum dinner } \\
\text { (17.00 hours) }\end{array}$ \\
\hline White bread & Turkey (slice) & Butter & $\begin{array}{l}\text { Strawberry yoghurt } \\
\quad(1.5 \% \text { fat })\end{array}$ & Meat lasagne \\
\hline Butter & Ham (slice) & Mayonnaise & Crisps & Chocolate granola bars \\
\hline Peanut butter & Salmon mousse & Ketchup & Apples & Water \\
\hline Cheddar cheese & Liver pâté & Italian dressing & Oranges & \\
\hline Orange juice & Gruyere cheese (28\% fat) & Mustard & Milk (2\% fat) & \\
\hline & Cottage cheese ( $2 \%$ fat) & Tomatoes & Dark soda & \\
\hline & White bread & Carrots & White soda & \\
\hline & Whole-wheat bread & Butter biscuits & Water & \\
\hline & Soda crackers & Chocolate fudge cookies & & \\
\hline
\end{tabular}

